\title{
Pengaruh Vibrasi Terhadap Kualitas Lapisan Tipis Opal yang Disintesis dengan Metode Deposisi Horizontal
}

\author{
Cecep Irwanda*, Muldarisnur \\ Laboratorium Fisika Material, Jurusan Fisika, \\ Fakultas Matematika dan Ilmu Pengetahuan Alam Universitas Andalas \\ Kampus Unand Limau Manis, Padang, 25163, Indonesia \\ *cecepirwanda@email.com
}

\begin{abstract}
ABSTRAK
Telah dilakukan sintesis dan karakterisasi lapisan tipis opal menggunakan metode deposisi horizontal dengan penambahan vibrasi. Sintesis dilakukan pada suhu ruang dengan variasi kecepatan vibrasi 0 , 1000, 1250, dan $1500 \mathrm{rpm}$ menggunakan magnetic stirrer. Karakterisasi dilakukan menggunakan Mikroskop Optik, SEM (Scanning Electron Microscopy) dan Spektrofotometer UV-Vis. Hasil mikroskop optik menunjukkan permukaan sampel dengan vibrasi lebih homogen dan tebal dibandingkan tanpa vibrasi. Hasil SEM menunjukkan lapisan multilayer terbentuk pada sampel vibrasi dengan kecepatan putaran $1500 \mathrm{rpm}$. Spektrum absobsi spektrofotometer UV-Vis menunjukkan nilai absorbansi maksimum tertinggi pada panjang gelombang $564 \mathrm{~nm}$ dengan nilai absorbansi 0,1526. Semakin tinggi kecepatan vibrasi yang digunakan, semakin tinggi nilai absorbansi maksimum dan semakin tinggi nilai FWHM.

Kata kunci: Deposisi horizontal, lapisan tipis, opal, polystyrene, vibrasi.
\end{abstract}

\section{ABSTRACT}

Thin oapl layers have been synthesized using horizontal depositioan method modified applying the addition at vibration. Synthesizing was carried out with at room temperature with vibration speed of 0 , 1000, 1250, and $1500 \mathrm{rpm}$. Characterization was carried of using optical microscope, SEM (Scanning Electron Microscopy) and UV-Vis Spectrophotometer. Characterization with optical microscope shows that vibration enhances thickner homogenity of opal sample. SEM show that multilayer layer is formed for sample deposition with vibration a $1500 \mathrm{rpm}$. The UV-Vis spectra show that the highest maximum absorbance of 0,1526 at wavelength of $564 \mathrm{~nm}$ for vibration of $1500 \mathrm{rpm}$. The higher the vibration speed used, the higher the maximum absorbance value and the higher the FWHM value.

Keywords: Horizontal depisition, thin layer, opal, polystyrene, vibration.

\section{PENDAHULUAN}

Kristal fotonik adalah struktur buatan dari sekurang-kurangnya dua bahan dielektrik periodik yang memiliki indeks bias berbeda dengan periodisitas (konstanta kisi) yang sebanding dengan panjang gelombang cahaya. Riset tentang kristal fotonik berkaitan dengan cara mengontrol propagasi, pemanduan, lokalisasi, dan emisi cahaya menggunakan bahan dielektrik yang memiliki indeks bias berubah secara periodik (Johnson dan Joannopoulos., 2002).

Interferensi destruktif antara cahaya yang dipantulkan pada setiap bidang batas medium yang berbeda membentuk celah pita optik (optical band gap). Adanya celah pita optik (band gap) pada kristal fotonik membuka peluang untuk realisasi devais fungsional seperti pandu gelombang, pembagi gelombang, serat kristal fotonik, light emitting diode, laser, sensor, dan masih banyak lagi.

Terdapat dua pendekatan dalam fabrikasi kristal fotonik, yaitu: top-down dan bottom-up. Pendakatan top-down menggunakan Teknik Litografi dan Holografi, sedangkan pendekatan bottom-up memanfaatkan kecenderungan alami partikel koloid untuk melakukan self-assembly. Self-assembly partikel koloid menghasilkan kristal fotonik 3D yang dikenal dengan opal.

Ada empat metode deposisi opal yang umum digunakan, yaitu: metode sedimentasi, metode deposisi horizontal, metode deposisi vertikal, dan metode deposisi kapiler. Metode sedimentasi sangat mudah dilakukan, namun menghasilkan struktur polikristal dan hanya dapat digunakan untuk partikel koloid yang tidak terlalu kecil dan tidak terlalu besar (Mi'guez dkk, 1998). Opal yang dihasilkan dengan metode deposisi vertikal memiliki kristalitas jauh lebih baik dibandingkan opal sedimentasi, namun memiliki ketebalan yang tidak homogen (Jiang dkk, 1999). Metode deposisi kapiler menghasilkan lapisan tipis opal dengan kualitas tinggi 
untuk semua ukuran partikel koloid dan dengan ketebalan lapisan tipis yang dapat dikontrol (Muldarisnur dan Marlow, 2011). Pada metode deposisi kapiler, opal di tumbuhkan di dalam sel planar yang harus dibuat secara khusus. Metode deposisi horizontal mempunyai beberapa kelebihan diantaranya: mudah dilakukan, dan dapat digunakan untuk partikel koloid dengan berbagai material dan ukuran. Kualitas lapisan tipis opal yang diperoleh dengan metode deposisi horizontal belum memadai dan ketebalan lapisan tidak homogen (Cai dkk, 2012).

Pada penelitian ini, lapisan tipis opal akan dideposisi menggunakan metode deposisi horizontal yang dimodifikasi dengan penambahan vibrasi. Vibrasi dapat meredistribusi suspensi ketika terjadi proses kristalisasi. Redistribusi partikel diharapkan menghasilkan lapisan tipis opal dengan kualitas tinggi dan dengan ketebalan yang homogen. Pada penelitian ini dianalisa pengaruh kecepatan vibrasi terhadap kristalitas dan homogenitas ketebalan lapisan tipis opal.

\section{METODE}

\subsection{Preparasi Bahan}

1. Persiapan bahan sebelum pembuatan lapisan tipis opal diantaranya:

2. Suspensi partikel koloid polystyrene yang berukuran $252 \mathrm{~nm}$ disiapkan.

3. Sebelum deposisi, larutan yang digunakan diaduk menggunakan Ultrasonic bath hingga larutan homogen.

\subsection{Sintesis Lapisan Tipis Opal}

1. Proses sintesis lapisan tipis opal adalah sebagai berikut:

2. Kaca substrat yang berukuran $20 \times 20 \mathrm{~mm}$ diletakkan di atas gelas.

3. Gelas diletakkan di atas magnetic stirrer.

4. Magnetic Stirrer dinyalakan dengan skala 1 atau dengan kecepatan $250 \mathrm{rpm}$.

5. Setelah magnetic stirrer dinyalakan, maka kaca substrat yang berada di atas gelas akan bervibrasi.

6. Larutan yang telah diaduk hingga homogen kemudian diteteskan ke atas permukaan kaca substrat yang bervibrasi.

7. Proses vibrasi dan pengendapan sampel berlangsung hingga 5 jam, koloid polystyrene yang dihasilkan ditunggu hingga kering.

8. Proses pengeringan sampel dilakukan pada suhu kamar. Pengeringan sampel dilakukan untuk menghilangkan kandungan air dari sampel lapisan tipis opal.

9. Perlakuan di atas dilakukan kembali dengan memvariasikan kecepatan vibrasi dalam rentang 4-6 (skala 1 pada magnetic stirrer sama dengan $250 \mathrm{rpm}$ ) hingga didapatkan sebanyak 3 buah sampel lapisan tipis opal.

\subsection{Karakterisasi Lapisan Tipis Opal}

Karakterisasi Mikroskop Optik dilakukan di Laboratorium Genetika Jurusan Biologi Universitas Andalas untuk melihat homogenitas lapisan tipis yang terbentuk. Karakterisasi SEM dilakukan di Pusat Penelitian dan Pengembangan Geologi Kelautan Bandung. Karakterisasi ini bertujuan untuk dapat memperoleh informasi mengenai morfologi lapisan tipis opal. Spektrofotometer UV-VIS digunakan untuk melihat posisi dan lebar celah pita optik pada lapisan tipis opal. Sampel dikarakterisasi menggunakan Spektrofotometer UV-VIS di Laboratorium Kimia Universitas Negeri Padang.

\subsection{Posisi Celah Pita Optik}

Posisi celah pita optik pada lapisan tipis dapat ditentukan dengan menggunakan persamaan Bragg;

$$
\Delta \lambda=2 \mathrm{n}_{\text {eff }} d_{h k l} \sin \theta
$$

dimana $\lambda_{B}$ adalah panjang gelombang Bragg, $n_{\text {eff }}$ adalah indeks bias efektif, dan $d_{h k l}$ adalah jarak antara bidang kristal.

$$
n_{\text {eff }}=n_{1} f+n_{2}(1-f)
$$


dimana $n_{1}$ adalah indeks bias medium pertama, $n_{2}$ indeks bias medium kedua, dan $f$ fraksi pengisian medium pertama. Lebar celah pita dapat ditentukan menggunakan Full-Width at Half of Maximum (FWHM) dari puncak Bragg.

\section{HASIL DAN DISKUSI}

\subsection{Lapisan Tipis Opal}

Hasil lapisan tipis opal yang disintesis menggunakan metode deposisi horizontal dapat dilihat pada Gambar 1. Gambar 1 menampilkan hasil sintesis lapisan tipis opal dengan penambahan vibrasi. Dari Gambar 1.(a sampai d) dapat dilihat lapisan tipis yang terbentuk pada semua sampel lebih tebal di bagian pinggir, sedangkan dibandingkan tengah hanya sebagian kecil terlapisi. Variasi ketebalan lapisan ini dikenal dengan efek cincin kopi (coffee-ring effect). Kosongnya bagian tengah disebabkan aliran partikel menuju meniskus (pinggir tetesan) menarik partikel dan membentuk lapisan yang lebih tebal di bagian pinggir tetesan sehingga bagian tengah dari lapisan tipis sering dibiarkan kosong (Mikolajek dkk., 2015).
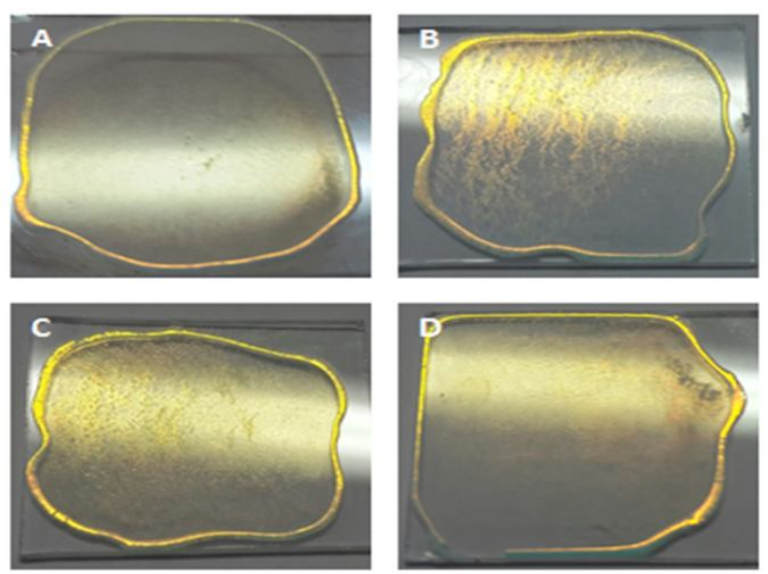

Gambar 1 Hasil sintesis lapisan tipis opal (a) tanpa vibrasi (b) vibrasi 1000 rpm (c) vibrasi $1250 \mathrm{rpm}$ (d) vibrasi $1500 \mathrm{rpm}$ menggunakan magnetic stirrer.

\subsection{Morfologi Permukaan}

Bentuk permukaan dari sampel diamati menggunakan alat mikroskop optik. Pengukuran dengan mikroskop optik dilakukan untuk mengamati morfologi sampel. Analisis mikroskop optik juga memberikan informasi bentuk permukaan sampel dan homogenitas dari sampel lapisan tipis.
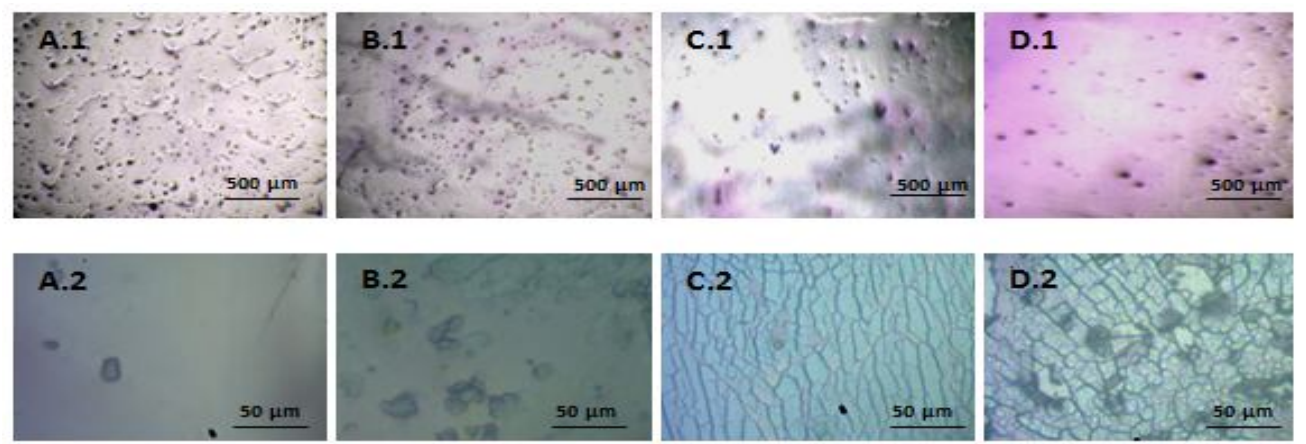

Gambar 2 Hasil pengukuran Mikroskop Optik degan perbesaran 4 kali dan 40 kali, (a.1 dan a.2) Sampel tanpa vibrasi (b.1 dan b.2) sampel vibrasi $1000 \mathrm{rpm}$ (c.1 dan c.2) sampel vibrasi $1250 \mathrm{rpm}$ (d.1 dan d.2) sampel $1500 \mathrm{rpm}$ menggunakan magnetic stirrer.

Hasil karakterisasi mikroskop optik dengan perbesaran 40 kali $(50 \mu \mathrm{m})$ pada Gambar 2.A.2 memperlihatkan sampel yang memantulkan warna keputihan. Warna putih menunjukkan lapisan yang terbentuk tidak teratur dan sangat tipis (common opal). Gambar 2.(b.2-d.2) terlihat 
lapisan yang terbentuk memantulkan variasi warna dari permukaan lapisan ketika dilihat dari sudut berbeda yang dikenal dengan precious opal.

Gambar 2.a.1 dapat dilihat permukaan dari sampel masih banyak memiliki spot yang belum terlapisi dan tidak terdapat retakan pada sampel yang menandakan lapisan yang terbentuk sangat tipis. Sedangkan Gambar 2.b.1 memperlihatkan permukaan sampel yang tidak homogen dan terdapat spot yang belum terlapisi pada lapisan tipis opal. Gambar 2.c.1 terlihat pada permukaan sampel memiliki retakan dan spot yang belum terlapisi. Gambar 2.d.1 menunjukkan dengan kecepatan vibrasi terdapatnya retakan dan terdapat spot yang belum terlapisi. Retakan pada sampel menandakan opal yang terbentuk cukup tebal (diatas $10 \mu \mathrm{m})$. Munculnya spot yang belum terlapisi disebabkan karena kurang bersihnya kaca substrat.

Homogenitas lapisan tipis opal dapat dilihat dari ketebalan dan sedikit spot yang belum terlapisi dari lapisan yang terbentuk. Ketebalan lapisan dapat dilihat dari retakan yang terdapat pada sampel. Retakan pada sampel menandakan bahwa bagian yang lebih tebal akan mudah terjadi retakan.

\subsection{Morfologi Permukaan}

Gambar 3 menunjukkan hasil Scanning Electron Microscope (SEM) bagian tengah dari sampel lapisan tipis opal dengan perbesaran 40.000 kali. Berdasarkan variasi penambahan kecepatan vibrasi yang telah dilakukan didapatkan hasil yang paling baik adalah pada vibrasi kecepatan $1500 \mathrm{rpm}$ (sampel d). Tapi dengan vibrasi kecepatan $1500 \mathrm{rpm}$ opal yang dihasilkan belum terlalu baik, perlu vibrasi yang lebih kuat untuk menghasilkan opal yang berkualitas. Hal ini disebabkan oleh vibrasi dengan kecepatan tinggi dapat menggetarkan permukaan cairan pada saat sintesis lapisan tipis. Meniskus dan aliran suspensi yang menarik partikel polystyrene kebagian pinggir lapisan dipengaruhi oleh vibrasi.
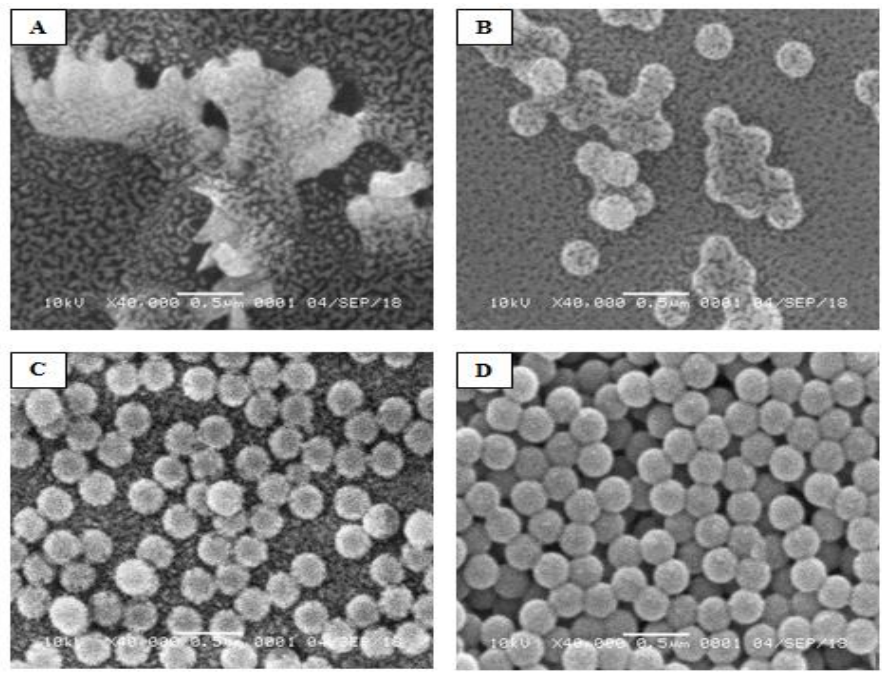

Gambar 3 Gambar SEM untuk sampel (a) tanpa vibrasi, (b) vibrasi 1000 rpm, (c) vibrasi $1250 \mathrm{rpm}$, dan (d) vibrasi $1500 \mathrm{rpm}$.

Berdasarkan variasi penambahan kecepatan vibrasi yang telah dilakukan didapatkan hasil yang paling baik adalah pada vibrasi kecepatan $1500 \mathrm{rpm}$ (sampel d). Tapi dengan vibrasi kecepatan $1500 \mathrm{rpm}$ opal yang dihasilkan belum terlalu baik, perlu vibrasi yang lebih kuat untuk menghasilkan opal yang berkualitas. Hal ini disebabkan oleh vibrasi dengan kecepatan tinggi dapat menggetarkan permukaan cairan pada saat sintesis lapisan tipis. Meniskus dan aliran suspensi yang menarik partikel polystyrene kebagian pinggir lapisan dipengaruhi oleh vibrasi.

\subsection{Analisis Karakterisasi Spektrofotometer UV-Vis}

Gambar 4 memperlihatkan spektrum absorbansi UV-Vis keempat sampel. Spektrum UV-Vis menunjukkan adanya puncak maksimum absorbansi pada panjang gelombang 400 $800 \mathrm{~nm}$. Spektrum UV-Vis untuk lapisan tipis opal yang disintesis tanpa penambahan vibrasi 302 
tidak memperlihatkan adanya puncak. Hal ini disebabkan partikel-partikel pada lapisan tidak membentuk kristal sehingga tidak terbentuk celah pita optik. Tidak adanya celah pita optik berakibat pada tidak terbentuknya puncak absorbansi. Sampel kedua dengan vibrasi $1000 \mathrm{rpm}$ pada magnetic stirrer memiliki puncak absorbansi maksimum sebesar 0,1022.

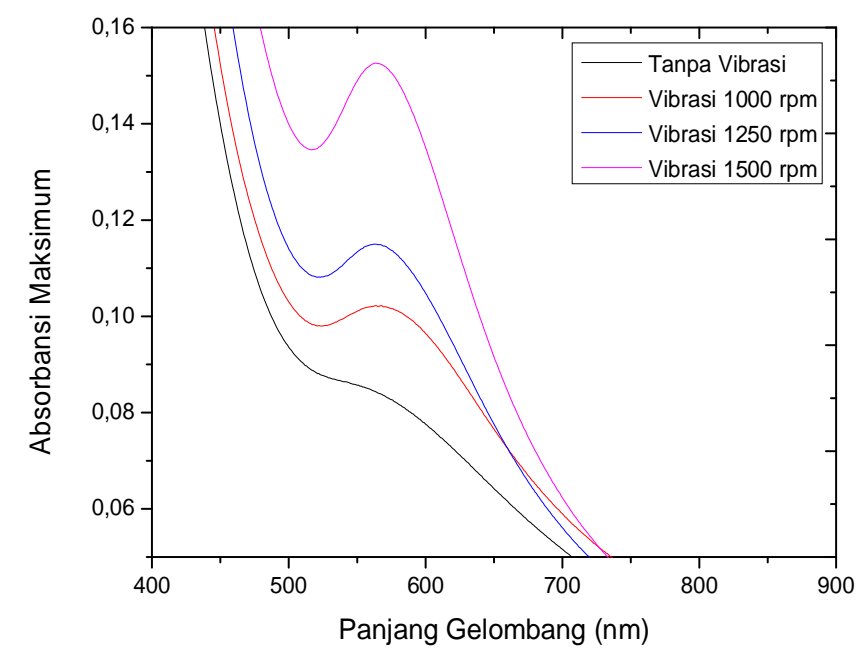

Gambar 4 Spektrum absorpsi UV-Vis lapisan tipis opal yang disintesis menggunakan metode deposisi horizontal tanpa vibrasi dan variasi penambahan vibrasi menggunakan kecepatan $1000 \mathrm{rpm}, 1250 \mathrm{rpm}$, dan $1500 \mathrm{rpm}$ pada magnetic stirrer.

Spektrum UV-Vis untuk vibrasi dengan kecepatan putaran $1250 \mathrm{rpm}$ memiliki puncak absorbansi maksimum sebesar 0,115. Nilai absorbansi paling besar terdapat pada sampel dengan vibrasi pada kecepatan putaran $1500 \mathrm{rpm}$ yaitu 0,1526 . Nilai absorbansi maksimum untuk sampel (b-d) terbentuk pada panjang gelombang $564 \mathrm{~nm}$. Data yang diperoleh dari spektrofotometer UV-Vis menunjukkan tidak terjadinya pergeseran puncak absorbansi dari sampel dengan penambahan vibrasi.

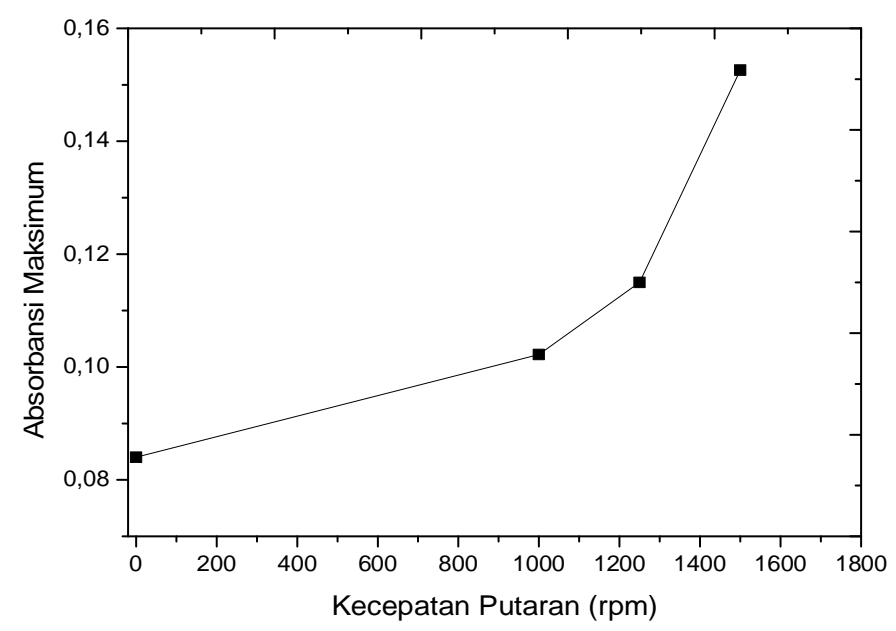

Gambar 5 Grafik perbandingan nilai absorbansi maksimum dengan kecepatan vibrasi.

Gambar 5 menunjukkan nilai absorbansi maksimum berbanding lurus dengan kecepatan vibrasi. Semakin tinggi kecepatan vibrasi maka semakin tinggi abosrbansi maksimum yang didapatkan. Puncak absorbansi menunjukkan adanya celah pita optik pada lapisan tipis opal. Keberadaan celah pita optik mengakibatkan cahaya dengan frekuensi dalam rentang band gap tidak dapat merambat dalam kristal fotonik sehingga semua cahaya dipantulkan. 


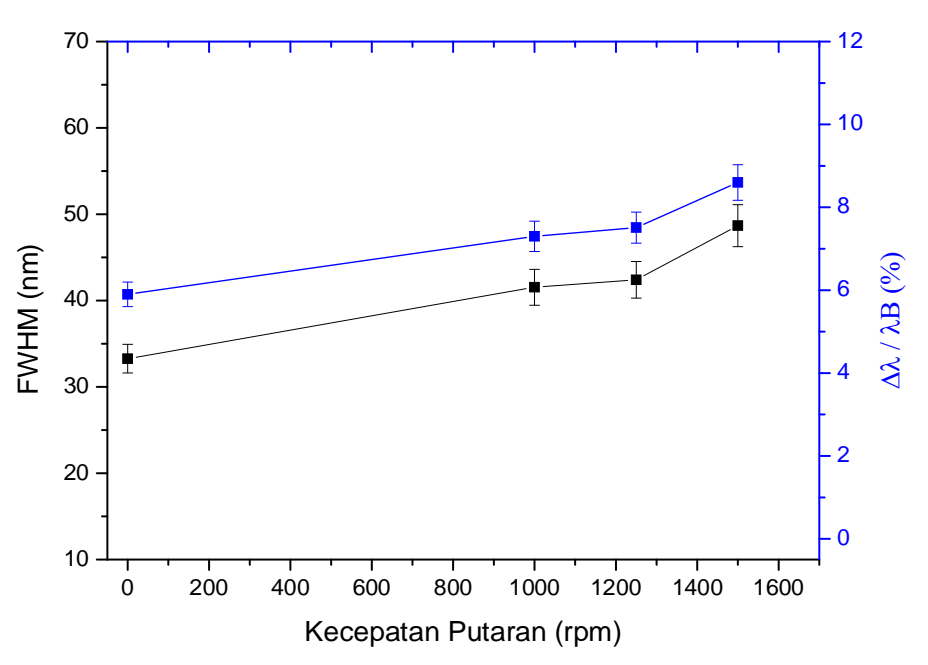

Gambar 6 Grafik perbandingan FWHM dan $\Delta \lambda / \lambda$ B terhadap vibrasi.

Gambar 6 menunjukkan perbandingan nilai FWHM dengan kecepatan vibrasi. Kecepatan vibrasi menunjukkan perubahan yang signifikan yaitu semakin besar kecepatan vibrasi maka nilai FWHM nya semakin besar. FWHM dapat menentukan lebar celah pita optik, karena FWHM sebanding dengan lebar celah pita optik (band gap) yang terbentuk pada lapisan tipis opal. Data grafik juga menunjukkan nilai $\Delta \lambda / \lambda_{B}$ untuk sampel dengan penambahan vibrasi adalah (7-8) \%.

\section{KESIMPULAN}

Berdasarkan hasil karakterisasi lapisan tipis opal yang disintesis menggunakan metode deposisi horizontal dapat disimpulkan bahwa: Homogenitas lapisan tipis opal bergantung pada kecepatan vibrasi. Semakin tinggi kecepatan vibrasi, semakin homogen dan semakin tebal lapisan lapisan tipis opal. Vibrasi yang digunakan tidak cukup kuat untuk mempengaruhi meniskus dan aliran suspensi menuju pinggir lapisan, sehingga lapisan yang terbentuk belum homogen dan tebal. Semakin tinggi kecepatan vibrasi yang digunakan, semakin tinggi kristalinitas opal yang dihasilkan.

\section{DAFTAR PUSTAKA}

Cai, Z.Y. Teng, J.H. Yan, Q.F. dan Zhao, X.S., 2012, Solvent effect on the self-assembly of colloidal microspheres via a horizontal deposition method, Colloids and Surfaces A: Physicochemical and Engineering Aspects Vol. 402, Hal. 37-44.

Jiang, P. Bertone, J. F. Hwang, K. S. dan Colvin. V. L., 1999, Single-crystal colloidal multilayers of controlled thickness, Chemical Mater, Vol. 11, Hal. 2132.

Johnson, S.G. dan Joannopoulos, J.D., 2002, Photonic Crystals: The Road from Theory to Practice, Kluwer Academic Publisher, Boston.

Míguez, H. Meseguer, F. López, C. Blanco, I. Moya, J.S. Requena, J. Mifsud, A. dan FornØs, V., 1998, Control of the Photonic Crystal Properties of fcc-Packed Submicrometer $\mathrm{SiO}_{2}$ Spheres by Sintering, Advanced Materials, Vol. 10, hal. 480-483.

Muldarisnur dan Marlow, F., 2011, Opal Films Made by the Capillary Deposition Method: Crystal Orientation and Defects, Journal of Physical Chemistry 115 (2), Hal. 414-418.

Mikolajek, M. Friederich, A. Bauer, W. Binder, J.R., 2015, Requirements to ceramic suspensions for inkjet printing, http://researchgate.net, diakses Maret 2018. 